УДК 782

ГРНТИ 18.41 .51

ПРАКТИЧЕСКАЯ РАБОТА ПО ПОСТАНОВКЕ ГОЛОСА, ЧАСТЬ І. ОБЩИЕ ПОЛОЖЕНИЯ

DOI: 10.31618/ESU.2413-9335.2020.11.74.812

Покровский Андрей Викторович

член-корреспондент

Петровской Академии наук и искусств.

Россия, г.Санкт-Петербург

\title{
PRACTICAL WORK ON VOICE TRAINING, PART I. GENERALITIES
}

Pokrovskiy A.V. corresponding member of the Peter Academy of Sciences and arts.

Russia, St. Petersburg

\begin{abstract}
The article examines the General provisions of vocal pedagogy: the relevance of the issue, principles, goals, objectives and methods of teaching singing; the criteria, methods of selection and basic skills necessary for those wishing to learn vocal art.
\end{abstract}

\section{АННОТАЦИЯ}

В статье исследуются общие положения вокальной педагогики: актуальность вопроса, принципы, цели, задачи и методы обучения пению; рассматриваются критерии, способы отбора и основные навыки, необходимые для желающих обучаться вокальному искусству. singing.

Key words: vocal, singing, academic singing, vocal pedagogy, voice production, methods of teaching

Ключевые слова: вокал, пение, академическое пение, вокальная педагогика, постановка голоса, методы обучения пению.

Обучение профессионального вокалиста занимает большой период времени, поскольку необходимо организовать и включить в работу целый ряд органов и систем, функции, которые в обычной жизни совершенно иные, однако в процессе пения они должны работать рефлекторно и слаженно, становясь частями единой системы.

Постановка голоса - это длительный процесс выработки специальных вокально-технических умений и навыков, формирование и тренировка голосового аппарата для его профессиональной работы. В процессе работы над профессиональной постановкой голоса, дифференцируется работа мышц, вырабатываются нужные психофизиологические рефлексы, а ненужные тормозятся. В результате голос приобретает требуемые критерии профессионального звучания.

\section{Актуальность}

Актуальность данного вида деятельности связана с важнейшими для современного человека вопросами духовно-нравственного, физического, интеллектуального и эмоционального развития личности, формирования картины мира и определения места человека в современном обществе.

\section{Цели и задачи}

Умение петь - навык, вырабатываемый многократным повторением действий, приводящих к необходимому результату. Овладение вокальными навыками требует постоянных методических тренировок, способствующих достижению определенных целей.

Узкопрофессиональные цели
-Организация работы голосовой системы посредством музыки и художественных образов.

-Овладение базовыми вокальными навыками.

- Постановка вокального дыхания.

-Освобождение от зажатости фонационных путей.

-Расширение звуковысотного

и динамического диапазона голоса.

Развивающие цели

-Развитие музыкального слуха.

-Развитие эмоциональной отзывчивости.

-Развитие художественного воображения.

Воспитательные цели

-Формирование мировоззрения и личностных качеств.

-Воспитание музыкального и художественного вкуса.

-Осознание потребности в творческой деятельности и способности к самовыражению.

•Освоение основ исполнительской культуры.

Достижению вышеперечисленных целей при обучении пению будет способствовать реализация следующих задач:

•освоение теории и методики пения;

•изучение строения голосового аппарата;

•знакомство с правилами гигиены и охраны голоса;

•отработка навыков певческого дыхания;

-освоение комплекса вокально-технических упражнений для развития голоса; 
•формирование установки;

•работа над артикуляции и дикции;

•развитие музыкальных способностей: слух, память, чувство ритма.

Принципы и методы вокальной педагогики

Традиционная школа вокального обучения, как правило, опирается на общепедагогические принципы: научный подход, постепенность и последовательность, воспитание, сознательность, практическое применение, индивидуальная направленность.

\section{Научный подход}

Принципы музыкального развития вокалиста базируются на научном знании. В своей работе вокальный педагог должен руководствоваться современными знаниями о голосовом аппарате, предоставляющими надежную методическую базу педагогической деятельности. Для того, чтобы хорошо ориентироваться в этой информации, педагог обязан предельно точно понимать суть каждого вокального явления и разбираться в том, как тот или иной прием влияет на голосовой аппарат.

Постепенность и последовательность

Данный принцип в процессе обучения пению подразумевает постепенный переход от простого к сложному при развитии технических навыков, освоение вокального репертуара и погружение в художественный образ.

\section{Воспитание}

Обучение пению имеет большую воспитательную силу. Вместе с развитием вокально-технических возможностей голосового аппарата и приобретением исполнительского опыта происходит совершенствование умственных, речевых и аналитических способностей, развивается воображение, тренируются личностные качества, нравственные, этические и мировоззренческие установки, что является важным для целостного развития человека.

\section{Сознательность}

Для верного понимания различных вокальных явлений огромное значение имеет сознательный подход в изучении причин положительных и отрицательных качеств певческого голоса. Важно иметь точное представление о профессиональном вокальном звуке и разбираться в том, какими приемами можно достичь его формирования или корректировки.

\section{Практическое применение}

Пение является одним из практических направлений музыкальной деятельности. Главной целью вокальных занятий является формирование и отработка профессиональных навыков, доведение их до состояния рефлекса.

Индивидуальная направленность

Певческий голос служит только инструментом. Сам феномен пения намного сложнее простого звуковедения. При помощи художественных образов он передает различные эмоциональные состояния и глубинные переживания человеческой души. Певец, как и всякий специалист, должен ориентироваться в большом количестве теоретических знаний для овладения вокальной техникой и свободного управления своим голосом. Однако обучиться вокальному искусству, владея только теорией, невозможно. Для освоения правильной техникой пения необходимы длительные регулярные практические занятия с педагогом.

Каждый человек уникален, обладает индивидуальным строением голосового аппарата, особым психологическим складом, внутренним миром и характером. Обязательное условие уроков вокала - индивидуальный подход. То есть преподаватель должен работать на уроке с одним учеником. Кроме преподавателя на уроке должен быть концертмейстер, аккомпанирующий вокалисту. Несоблюдение этого подхода к каждому отдельному обучающемуся неизбежно приведет к снижению эффективности урока и качества обучения.

\section{Методы обучения}

Традиционно в профессиональном вокальном обучении используются следующие методы:

-Словесное объяснение.

Подразумевает передачу сведений о голосообразовании при помощи устного слова. Данный метод направлен на логическое осмысление, анализ и запоминание информации.

-Показ педагогом верного звучания.

Предполагает воспроизведение педагогом необходимого звучания при помощи голосового показа. Этот метод формирует представление о верном звучании через подсознательную сферу обучающегося.

Данный метод обладает большим эмоциональным и эстетическим воздействием и через наглядный показ дает возможность достигнуть необходимого результата через подражание. При использовании этого метода педагог должен учитывать, что скопированы могут быть не только положительные, но и отрицательные качества звучания голоса. Поэтому очень важно, чтобы показ был правильным и приближенным к идеальному звучанию.

Оба этих репродуктивных метода направлены на качественное, быстрое освоение основ профессиональных вокально-технических навыков.

-Эвристический метод.

Применяется для художественного развития личности и музыкально-исполнительских способностей. Суть метода заключается в том, что учащийся в результате самостоятельной работы пытается найти оптимальное выражение, характер звучания и образное решение исполняемого произведения. Этот метод призван задействовать эмоциональную сферу сознания учащегося и его жизненный опыт.

Направления учебной работы

-Музыкально-теоретическая подготовка.

•Вокальное исполнительство: ансамбль, соло. 
•Концертно-исполнительская деятельность. Отбор обучающихся

Основное требования при зачислении для обучения пению: слух, выраженные вокальные данные, чувство ритма и наличие художественной выразительности. Общее представление об этом дает исполнение несложного вокального произведения, повторение простых ритмических рисунков и проверка диапазона во время вступительных испытаний. Из-за сильного волнения испытуемый может недостаточно проявить себя на прослушивании, однако при регулярных занятиях, к концу первого месяца обучения, данные начинающего вокалиста будут определены вполне объективно. Во время вступительных испытаний могут быть также выявлены некоторые недостатки, которые должны быть приняты во внимание педагогами для скорейшего их устранения.

Для удобства проведения вступительных испытаний можно использовать простую письменную форму:

\begin{tabular}{|c|c|c|c|}
\hline \multicolumn{4}{|c|}{ Лист вступительных испытаний } \\
\hline \multicolumn{4}{|c|}{ Общие сведения: } \\
\hline \multicolumn{4}{|c|}{ ФИО испытуемого } \\
\hline Возраст & Пол & Тембр голоса & $\begin{array}{c}\text { Предыдущий опыт } \\
\text { занятий вокалом }\end{array}$ \\
\hline \multicolumn{4}{|c|}{$\begin{array}{l}\text { Исполненные } 1 . \\
\text { произведения } 2 . \\
3 .\end{array}$} \\
\hline \multicolumn{2}{|c|}{ Ритмическая память } & \multicolumn{2}{|c|}{ Диапазон } \\
\hline \multicolumn{4}{|c|}{ Выявленные недостатки голоса } \\
\hline Гнусавость & Крикливость & Фальшивое пение & $\begin{array}{c}\text { Повышенная } \\
\text { стеснительность }\end{array}$ \\
\hline Картавость & Плоское звучание & Поверхностное дыхание & Повышенная активность \\
\hline Шепелявость & Сип & Слабая муз. память & Вялая артикуляция \\
\hline \multicolumn{4}{|c|}{ Другое: } \\
\hline \multicolumn{4}{|c|}{$\begin{array}{c}\text { Общее представление } \\
\text { об испытуемом }\end{array}$} \\
\hline \multicolumn{3}{|c|}{$\begin{array}{c}\text { ФИО проводившего испытания } \\
1 . \\
2 . \\
3 . \\
\end{array}$} & $\begin{array}{c}\text { Дата проведения } \\
\text { испытания: }\end{array}$ \\
\hline
\end{tabular}

Список использованной литературы: 2000

1.Багадуров В. Вокальное воспитание. - СПб.

2.Варламов А. Школа пения. - СПб. 2008 2018

3.Выготский Л. Психология искусства. - М.

4.Гарсиа М. Полная школа пения. - М. 1957

5.Далецкий О. Школа пения. - М. 2007

6.Дейша-Сионицкая М. Пение в ощущениях. СПб. 2014

7.Дмитриев Л. В классе профессора М.Э. Донец-Тессейр. - М. 1974

8.Дмитриев Л. Основы вокальной методики. М. 2000

9.Емельянов В. Развитие голоса. - СПб. 2003

Исторические науки
10.Кабалевский Д. Воспитание ума и сердца. M. 1981

11.Лемешев С. Путь к искусству. - М. 1982

12.Матонис В. Музыкально-эстетическое воспитание личности. - Л. 1988

13.Морозов В. Искусство резонансного пения. - M. 2002

14.Назаренко И. Искусство пения. - М.-Л. 1948

15.Павлищева О. Методика постановки голоса. - Л. 1964

16.Панофка Г. Искусство пения. - М. 1968

17.Фучито С., Бейер Б. Вокальная методика Энрико Карузо. - СПб. 2004

18.Юшманов В. Вокальная техника и ее парадоксы. - СПб. 2001 